\title{
Amyloid-beta 42 adsorption following serial tube transfer
}

\author{
Jamie Toombs ${ }^{1 *}$, Ross W Paterson², Jonathan M Schott ${ }^{2}$ and Henrik Zetterberg ${ }^{1,3}$
}

\begin{abstract}
Introduction: Cerebrospinal fluid (CSF) amyloid-beta 38 (Aß38), 40 (Aß40), 42 (Aß42) and total tau (T-tau) are finding increasing utility as biomarkers of Alzheimer's disease (AD). The purpose of this study was to determine whether measured CSF biomarker concentrations were affected by transfer of CSF between tubes, and whether addition of a non-ionic surfactant mitigates any observed effects.

Methods: AD and control CSF was transferred consecutively between polypropylene tubes. A $\beta$ peptides and T-tau were measured with and without addition of Tween 20 (0.05\%).

Results: Measured concentrations of $A \beta 42$ decreased by approximately 25\% with each consecutive transfer. Measured concentrations of $A \beta 38$ and $A \beta 40$ were also observed to decrease significantly with each consecutive transfer (approximately 16\% loss per transfer). Measured concentrations of T-tau also decreased significantly, but at much smaller magnitude than the A $\beta$ peptides (approximately 4\% loss per transfer). The addition of Tween 20 mitigated this effect in all samples.

Conclusions: Consecutive CSF transfer between tubes has a significant impact on the measured concentration of all $A \beta$ peptides, and significant effect of lesser magnitude on T-tau. This would be sufficient to alter biomarker ratios enough to mislead diagnosis. The introduction of Tween 20 at the initial aliquoting stage was observed to significantly mitigate this effect.
\end{abstract}

\section{Introduction}

Cerebrospinal fluid (CSF) amyloid beta 38 (A 338 ), amyloid beta 40 (A 340$)$, amyloid beta $42(\mathrm{~A} \beta 42)$ and total tau (T-tau) are protein biomarkers used in the clinical diagnosis and research analysis of, and drug development for, Alzheimer's disease (AD). Inter-site variation in the measured concentration of these proteins, even in the same samples, is well-recognised. Known confounding factors in the measurement of $A \beta$ and tau concentrations include delays in sample analysis [1], diurnal variation [2], CSF contamination with blood or breakdown of the blood brain barrier [3,4], choice of storage tube material $[5,6]$ and sample storage volume [7]. The hydrophobic nature of $A \beta 42$ and its propensity to be adsorbed to the walls of collection containers, as well as to aggregate with itself and other proteins [3], appears to make this peptide more vulnerable to these influences than many other analytes.

\footnotetext{
* Correspondence: j.toombs@ucl.ac.uk

${ }^{1}$ Department of Molecular Neuroscience, Institute of Neurology, University College London, Queen Square, London, UK

Full list of author information is available at the end of the article
}

Following an anomalous decrease in assayed $A \beta 42$ concentration in the same CSF between two laboratories, an investigation was made to ascertain the cause. As the CSF tested was the same this ruled out collection factors as a likely variable. Additionally, both laboratories had assayed the sample using the same protocol, suggesting that differences in technique and timing, though impossible to eliminate, should have been minimal. Based on the propensity for certain proteins to adsorb to container surfaces it was hypothesised that, as CSF is transferred between surfaces (for example, tubes) the concentration of these proteins in solution would decrease. Given a standardised volume, it was also conjectured that this concentration decrease would be linear, with a relative proportion of the protein being lost at each step. It was predicted that the $A \beta$ peptides would behave in this way, and that T-tau would not be significantly affected. Furthermore, this study explored whether such effects could be mitigated by pre-treating the sample with a non-ionic surfactant (Tween 20, also known

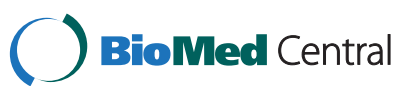


as polysorbate 20) known to reduce tube surface adsorption and/or aggregation of $A \beta 42$ [7-9].

\section{Methods \\ Assays \\ Pilot}

We conducted an initial pilot study to demonstrate proof of concept, which was then followed by a larger experiment consisting of three replicate rounds. All assays were run on a Meso Scale Discovery 6000 platform. The pilot experiment used MSD Human A $\beta 42$ and MSD Human Total Tau kits (Meso Scale Discovery, Gaithersburg, MD, USA). Samples were added to $A \beta 42$ and T-tau plates in triplicate.

\section{Replication}

The replication experiment used MSD Human A $\beta 42$ (V-plex), MSD Human Total Tau kits (V-plex) and MSD A $\beta$ Peptide Panel 1 (this panel is a triplex assay measuring $A \beta 38, A \beta 40$ and $A \beta 42$ using $6 E 10$ in combination with neoepitope-specific antibodies to the different $\mathrm{A} \beta \mathrm{C}$-termini) (V-plex). $\mathrm{V}$-plex refers to the updated validation versions that superseded the same kits used in the pilot at the time of these experiments. Samples were added to $\mathrm{T}$-tau and $\mathrm{A} \beta$ peptide plates in duplicate. Each assay was repeated at 24 hour intervals a total of three times. The kit manufacturer's protocol was followed for all pilot and replicate assays.

\section{Sample pools}

This study tested two pools of de-identified CSF. The first was from a cohort of subjects with CSF biomarker profiles consistent with $\mathrm{AD}$ pathology. The combination of A $342<530 \mathrm{ng} / \mathrm{L}$ and T-tau $>350 \mathrm{ng} / \mathrm{L}$ taken together have a sensitivity and specificity for diagnosing $\mathrm{AD}$ pathology of approximately $90 \%$ [4]. The second pool was from non-AD control (CTRL) CSF (biomarker concentrations within the normal range: $\mathrm{A} \beta 42 \geq 530 \mathrm{ng} / \mathrm{L}$ and $\mathrm{T}$-tau $\leq 350 \mathrm{ng} / \mathrm{L}$ ). These value ranges are based on Innogenetic's INNOTEST A $\beta 42$ and hTau assays, respectively. Ethical approval was received from the regional ethics board at the University of Gothenburg for the CSF pools used in this study. According to Swedish legislation, informed consent is not required for de-identified CSF samples.

\section{Pilot}

The two pools were provided, pre-mixed and pre-spun, by the Clinical Neurochemistry Laboratory at the Sahlgrenska University Hospital, Sweden, in Greiner Bio-one (Frickenhausen, Germany) polypropylene (PP), sterile, $50 \mathrm{~mL}$ tubes (cat. 210261). Each pool was split into two $25 \mathrm{~mL}$ aliquots, $12.5 \mu \mathrm{L}$ Tween 20 (0.05\%) was introduced to one aliquot, and the other was kept neat. From these pools four $925 \mu \mathrm{L}$ aliquots were derived - Neat AD (NAD), Tween AD (TAD), Neat control (NCT), and Tween control (TCT). These aliquots were stored in Sarstedt (Nümbrecht, Germany), PP, DNase/RNase free, $2 \mathrm{~mL}$ screw top tubes (cat. 72.694.406).

\section{Replication}

Two pools of CSF were provided by the Clinical Neurochemistry Laboratory at the Sahlgrenska University Hospital, Sweden. These pools were not of the same CSF as those used in the pilot, but met the same criteria for $\mathrm{AD}$ and CTRL detailed above. Samples were received in eight Sarstedt $10 \mathrm{~mL}$, screw cap, PP tubes (cat: 62.9924.284), four $\mathrm{AD}$ and four CTRL. Both AD and CTRL pools were treated by the same procedure which follows, and is illustrated in Figure 1. The four original sample tubes were thawed at room temperature for one hour, then pooled together into a $100 \mathrm{~mL}$ Sarstedt PP beaker (cat. 75.1354.001). The mixed CSF was then transferred into a $50 \mathrm{~mL}$ Greiner tube and then spun at 3,000 rpm for 10 minutes at $4^{\circ} \mathrm{C}$ (the same method used in the pilot). Two $10 \mathrm{~mL}$ aliquots were then created in empty $50 \mathrm{~mL}$ Greiner tubes. A total of $5 \mu \mathrm{L}$ of Tween $20(0.05 \%)$ was added to one of these newly created tubes. These $10 \mathrm{~mL}$ aliquots were each divided into $1 \mathrm{~mL}$ aliquots to form neat and Tween storage tube batches. The tubes used for storage were the same as in the pilot. The result of this process was ten $1 \mathrm{~mL}$ aliquots of four different types - Neat AD (NAD), Tween AD (TAD), Neat control (NCT), and Tween control (TCT). The word 'neat' is used in this paper to distinguish the sample which did not contain Tween 20, it does not denote dilution.

\section{Sample treatment \\ Pilot}

At the start of the experiment, the four sample aliquots (NAD, TAD, NCT, TCT) were thawed together at room temperature for approximately one hour. A portion of CSF from each was then transferred consecutively to seven other tubes. Starting with Tube 0 (the storage aliquot) with $925 \mu \mathrm{L}, 710 \mu \mathrm{L}$ was transferred to Tube $1 ; 510 \mu \mathrm{L}$ was then transferred from Tube 1 to Tube 2; $310 \mu \mathrm{L}$ from Tube 2 to Tube 3; and $110 \mu \mathrm{L}$ from Tube 3 to Tube 4. Thus, the volumes in the experiment aliquots were as follows: Tube $0=215 \mu \mathrm{L}$, Tube $1=200 \mu \mathrm{L}$, Tube $2=200 \mu \mathrm{L}$, Tube $3=200 \mu \mathrm{L}$, and Tube $5=110 \mu \mathrm{L}$. Tube 5 had a lower volume due to total volume restrictions. A $\beta 42$ and T-tau aliquots were dispensed into the same disposable PP plate for dilution at factors $1: 8$ and 1:2, respectively.

\section{Replication}

It was recognised that the transfer volumes used in the pilot were inconsistent and that this was a flaw in its design. Therefore, these were adjusted in the replication study to be uniform. Additionally, three extra transfer steps were included in the transfer series of the replication. At the start of the experiment the four 


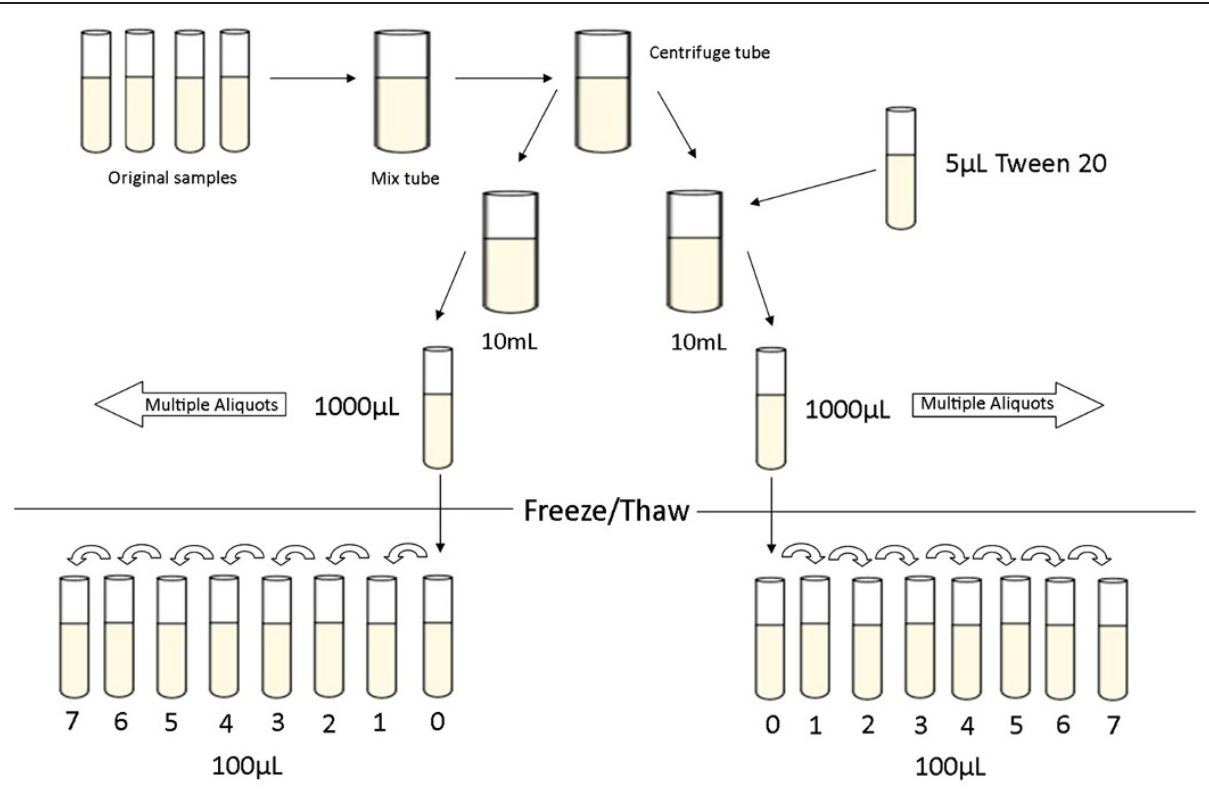

Figure 1 Diagram showing the sample preparation process conducted for the replication experiment. The same process was used in the pilot with the exception of different volumes, as detailed in the Methods section.

sample aliquots (NAD, TAD, NCT, TCT) were thawed together at room temperature for approximately one hour. A portion of CSF from each was then transferred consecutively to seven other tubes, leaving $100 \mu \mathrm{L}$ in each (Figure 1). Starting with Tube 0 (the storage aliquot) with $1,000 \mu \mathrm{L}, 900 \mu \mathrm{L}$ was transferred to Tube $1 ; 800 \mu \mathrm{L}$ was then transferred from Tube 1 to Tube 2 and so on until $200 \mu \mathrm{L}$ was transferred from Tube 7 to an eighth tube not used in the study; thus, the tubes used in the experiment (tubes 0 to 7 ) each contained $100 \mu \mathrm{L}$ of pooled CSF. After the creation of this transfer series, the samples had their anonymised identifiers (for example, NAD1, NAD2 and so on) obscured by tape and were rearranged and relabelled 1 to 32 (that is, eight tubes for each of NAD, TAD, NCT and TCT) by a colleague not otherwise participating in the study. Thus blinded, sample aliquots were dispensed into a disposable PP plate for dilution. This had not been done in the pilot. The used tubes were kept in the order they were aliquoted to the plate. After the data had been collected the tape was removed and the identifiers matched with their respective plate wells (for sample identification please see Additional file 1). Dilution factors for A $\beta 42$, T-tau and A $\beta$ Peptide Panel assays were 1:8, 1:4 and 1:2, respectively, as recommended by the kit protocol. The dilution factor for T-tau differed from the pilot due to volume restrictions imposed by the $100 \mu \mathrm{L}$ transfer volume.

All solutions, in both the pilot and replication, were mixed by uninterrupted vortexing for five seconds, and all pipette tips were pre-wetted with three pumps.

\section{Statistical analysis}

Linear regression was used to examine the relationship between analyte concentration values and number of sample transfers. The median of the measured analyte concentration values was the dependent variable, and the number of transfers was the independent variable of interest. In the replication study, day (that is, assay repeat) was incorporated as a covariate. All statistical analyses were conducted in Stata Version 12.1. Graphs were created using SPSS version 21.

\section{Results \\ Aß42 pilot}

Figure 2A shows the results of the pilot study for an $A \beta 42$ single-plex assay. One transfer of neat AD CSF predicted a change in measured A 442 concentration of $-36.2 \mathrm{pg} / \mathrm{mL}$, (95\% confidence interval (CI): -47.2 to $-25.1 \mathrm{pg} / \mathrm{mL}$, $P=0.002)$. The average percentage difference per transfer was $27.0 \%$ of the starting value. For neat control CSF this predicted change was $-72.1 \mathrm{pg} / \mathrm{mL}$ (CI: -78.4 to $-65.8 \mathrm{pg} / \mathrm{mL}, P=<0.005)$. The average percentage difference per transfer was $28.6 \%$. Tween 20 acted to mitigate the magnitude of this decrease in both pools. One transfer of AD CSF in the presence of Tween 20 predicted a change in measured $A \beta 42$ concentration of $-9.9 \mathrm{pg} / \mathrm{mL}$ (CI: -16.6 to $-3.2 \mathrm{pg} / \mathrm{mL}, P=0.018$ ). The average percentage difference per transfer was 5.1\%. For control CSF with added Tween the trend was a non-significant $-27.2 \mathrm{pg} / \mathrm{mL}$ (CI: -70.7 to $+16.3 \mathrm{pg} / \mathrm{mL}, P=0.14$ ). The average percentage difference per transfer was $4.9 \%$. 


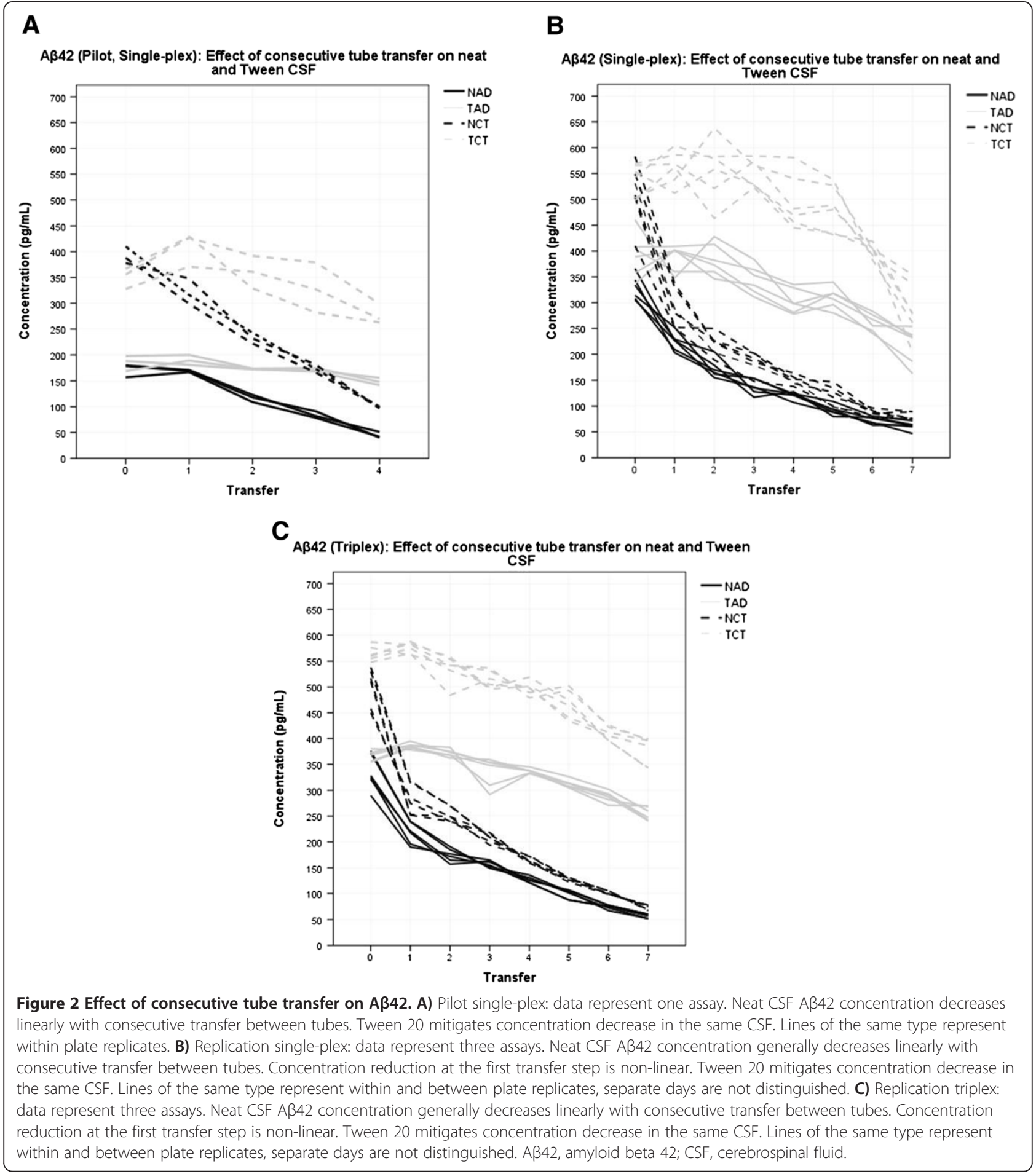

\section{$A \beta 42$ replication}

Figure $2 \mathrm{~B}$ presents the data for the single-plex $A \beta 42$ over three separate assays. Over seven transfers, one transfer of neat AD CSF predicted a change in measured $A \beta 42$ concentration of $-37.3 \mathrm{pg} / \mathrm{mL}$ (CI: -40.6 to $-28.3 \mathrm{pg} / \mathrm{mL}$, $P=<0.005)$. The average percentage difference per transfer was $21.1 \%$ of the starting value. For neat control
CSF this predicted change was $-52.2 \mathrm{pg} / \mathrm{mL}$ (CI: -64.8 to $-39.7 \mathrm{pg} / \mathrm{mL}, P=<0.005)$. The average percentage difference per transfer was $22.7 \%$. Tween 20 acted to mitigate the magnitude of this decrease in both pools. One transfer of AD CSF with Tween 20 predicted a change in measured A $\beta 42$ concentration of $-25.2 \mathrm{pg} / \mathrm{mL}$ (CI: -29.5 to $-20.9 \mathrm{pg} / \mathrm{mL}, P=<0.005$ ). The average 
percentage difference per transfer was $7.8 \%$. For control CSF with added Tween one transfer predicted a change in measured A $\beta 42$ concentration of $-34.0 \mathrm{pg} / \mathrm{mL}$ (CI: -44.9 to $-23.1 \mathrm{pg} / \mathrm{mL}, P=<0.005)$. The average percentage difference per transfer was $8.0 \%$.

\section{Aß42 (triplex) replication}

Figure $2 \mathrm{C}$ presents the data for the triplex $\mathrm{A} \beta 42$ over three separate assays. Over seven transfer steps, one transfer of neat AD CSF predicted a change in measured A $\beta 42$ concentration of $-34.9 \mathrm{pg} / \mathrm{mL}$ (CI: -40.9 to $-28.8 \mathrm{pg} / \mathrm{mL}$, $P=<0.005)$. The average percentage difference per transfer was $22.2 \%$ of the starting value. One transfer of neat control CSF predicted a change in measured $\mathrm{A} \beta 42$ concentration of $-41.4 \mathrm{pg} / \mathrm{mL}$ (CI: -62.0 to $-40.9 \mathrm{pg} / \mathrm{mL}, P=<0.005$ ). The average percentage difference per transfer was $23.4 \%$. Tween 20 acted to mitigate the magnitude of this decrease in both pools. In AD CSF with Tween 20 one transfer step predicted a concentration change of $-17.3 \mathrm{pg} / \mathrm{mL}$ (CI: -20.7 to $-13.9 \mathrm{pg} / \mathrm{mL}, P=<0.005)$. The average percentage difference per transfer was $4.9 \%$. In control CSF with Tween 20 one transfer step predicted a concentration change of $-28.1 \mathrm{pg} / \mathrm{mL}$ (CI: -32.6 to $-23.7 \mathrm{pg} / \mathrm{mL}, P=<0.005)$. The average percentage difference per transfer was $5.5 \%$.

\section{A $\beta 38$ (triplex) replication}

Figure $3 \mathrm{~A}$ presents the data for the triplex $A \beta 38$ over three separate assays. Over seven transfer steps, one transfer of neat AD CSF predicted a change in measured $\mathrm{A} \beta 38$ concentration of $-330.2 \mathrm{pg} / \mathrm{mL}$ (CI: -359.3 to $-301.0 \mathrm{pg} / \mathrm{mL}$, $P=<0.005)$. The average percentage difference per transfer was $16.0 \%$ of the starting value. One transfer of neat control CSF predicted a change in measured $\mathrm{A} \beta 38$ concentration of $-224.0 \mathrm{pg} / \mathrm{mL}$ (CI: -241.8 to $-206.3 \mathrm{pg} / \mathrm{mL}, P=<0.005$ ). The average percentage difference per transfer was $16.1 \%$. Tween 20 acted to mitigate the magnitude of this decrease in both pools. In AD CSF with Tween 20 one transfer step predicted a concentration change of $-53.1 \mathrm{pg} / \mathrm{mL}$ (CI: -78.9 to $-27.3 \mathrm{pg} / \mathrm{mL}, P=<0.005$ ). The average percentage difference per transfer was $1.4 \%$. In control CSF with Tween 20 one transfer step predicted a concentration change of $-38.4 \mathrm{pg} / \mathrm{mL}$ (CI: -53.5 to $-23.4 \mathrm{pg} / \mathrm{mL}$, $P=<0.005)$. The average percentage difference per transfer was $1.1 \%$.

\section{A $\beta 40$ (triplex) replication}

Figure $3 \mathrm{~B}$ presents the data for the triplex $\mathrm{A} \beta 40$ over three separate assays. Over seven transfer steps, one transfer of neat AD CSF predicted a change in measured $\mathrm{A} \beta 40$ concentration of $-676.5 \mathrm{pg} / \mathrm{mL}$ (CI: -724.7 to $-628.2 \mathrm{pg} / \mathrm{mL}$, $P=<0.005)$. The average percentage difference per transfer was $15.6 \%$ of the starting value. One transfer of neat control CSF predicted a change in measured $\mathrm{A} \beta 40$ concentration of $-513.3 \mathrm{pg} / \mathrm{mL}$ (CI: -554.0 to $-472.7 \mathrm{pg} / \mathrm{mL}, P=<0.005)$. The average percentage difference per transfer was $17.5 \%$. Tween 20 acted to mitigate the magnitude of this decrease
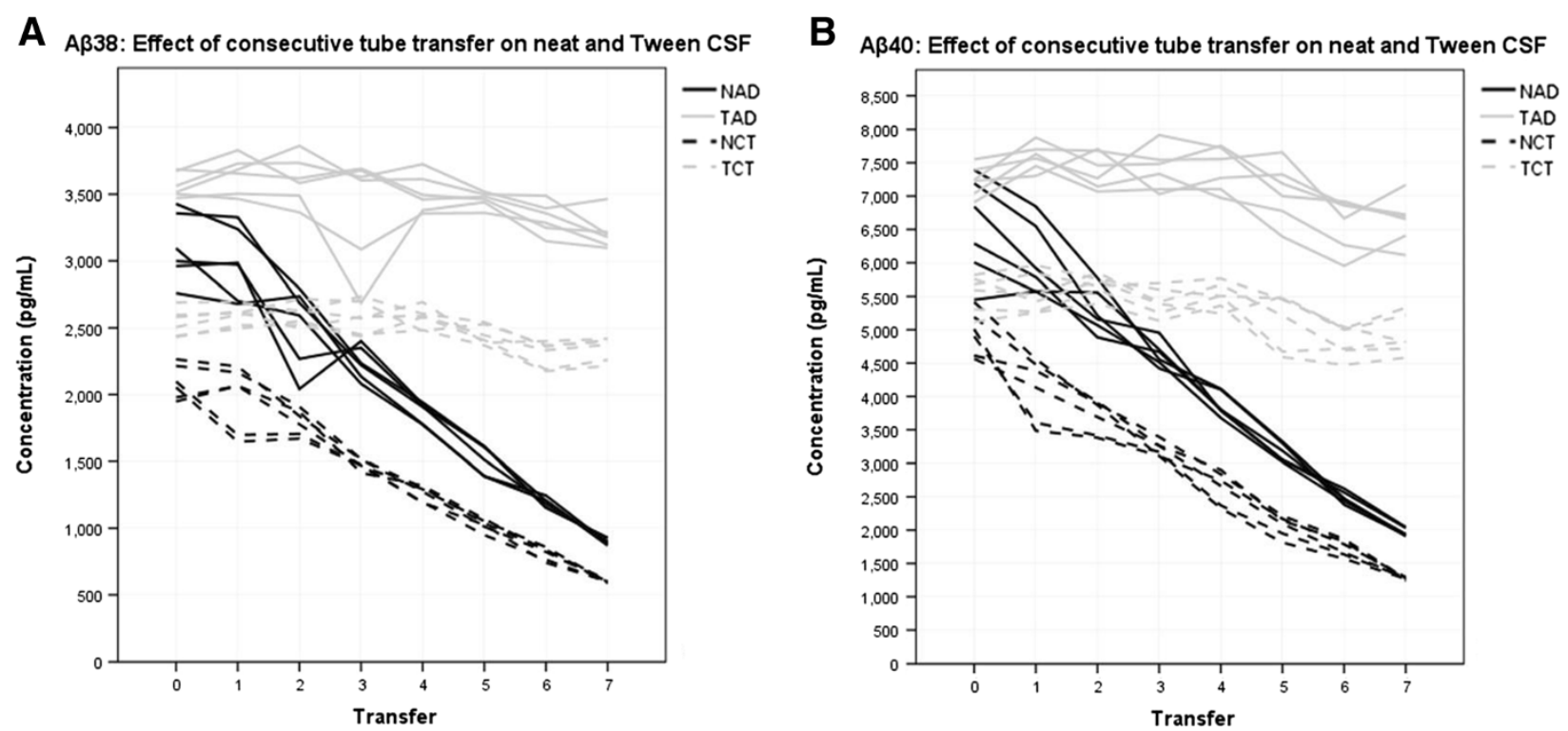

Figure 3 Effect of consecutive tube transfer on A $\mathbf{\beta 3 8}$ and A $\boldsymbol{\beta} 40$. A) Replication: data represent three assays. Neat CSF A 338 concentration decreases linearly with consecutive transfer between tubes. Tween 20 mitigates the concentration decrease in the same CSF. Lines of the same type represent within and between plate replicates, separate days are not distinguished. B) Replication: data represent three assays. Neat CSF A 340 concentration decreases linearly with consecutive transfer between tubes. Tween 20 mitigates the concentration decrease in the same CSF. Lines of the same type represent within and between plate replicates, separate days are not distinguished. A 338 , amyloid beta 38; $A \beta 40$, amyloid beta 40; CSF, cerebrospinal fluid. 
in both pools. In AD CSF with Tween 20 one transfer step predicted a concentration change of $-121.5 \mathrm{pg} / \mathrm{mL}$ (CI: -174.7 to $-68.4 \mathrm{pg} / \mathrm{mL}, P=<0.005$ ). The average percentage difference per transfer was $1.2 \%$. In control CSF with Tween 20 one transfer step predicted a concentration change of $-112.9 \mathrm{pg} / \mathrm{mL}$ (CI: -152.2 to $-73.6 \mathrm{pg} / \mathrm{mL}$, $P=<0.005)$. The average percentage difference per transfer was $1.6 \%$.

\section{T-tau pilot}

Figure 4A shows that the concentration of T-tau did not decrease significantly with consecutive transfer of CSF between tubes: there was a trend for a decline in measured T-Tau concentration in neat $\mathrm{AD}$ and control CSF $(-93.8 \mathrm{pg} / \mathrm{mL}, \mathrm{CI}:-194.9$ to $+7.3, P=0.060,5.1 \%$; and $-34.5 \mathrm{pg} / \mathrm{mL}, \mathrm{CI}:-73.3$ to $+4.3 \mathrm{pg} / \mathrm{mL}, P=0.066$, $5.8 \%$ respectively), but no evidence for a decline with measured T-Tau concentration in $\mathrm{AD}$ and control CSF with Tween $(14.2 \mathrm{pg} / \mathrm{mL}, \mathrm{CI}:-94.7$ to $+123.1 \mathrm{pg} / \mathrm{mL}, P=0.706$, $0.4 \%$; and $-14.8 \mathrm{pg} / \mathrm{mL}, \mathrm{CI}:-38.8$ to $+10.0 \mathrm{pg} / \mathrm{mL}, P=$ $0.157,1.6 \%$ respectively).

\section{T-tau replication}

Figure 4B demonstrates the data for T-tau over three separate assays. Over seven transfers, one transfer of neat AD CSF predicted a change in measured T-Tau concentration of $-24.5 \mathrm{pg} / \mathrm{mL}$ (CI: -39.4 to $-9.5 \mathrm{pg} / \mathrm{mL}$, $P=0.003)$. The average percentage difference per transfer was $4.4 \%$ of the starting value. For neat control CSF this predicted change was $-11.6 \mathrm{pg} / \mathrm{mL}$ (CI: -17.4 to $-5.9 \mathrm{pg} / \mathrm{mL}$, $P=<0.005)$. The average percentage difference per transfer was $3.5 \%$. One transfer of AD CSF with Tween 20 did not demonstrate a significant change in measured T-Tau concentration; T-Tau: $-1.6 \mathrm{pg} / \mathrm{mL}$ (CI: -7.4 to $+4.1 \mathrm{pg} / \mathrm{mL}$, $P=0.558$ ). The average percentage difference per transfer was $0.2 \%$. For control CSF with added Tween one transfer did not predict a significant change in measured T-Tau concentration: $-0.4 \mathrm{pg} / \mathrm{mL}$ (CI: -4.0 to $+3.2 \mathrm{pg} / \mathrm{mL}$, $P=0.828)$. The average percentage difference per transfer was $0.5 \%$.

All results are summarised in Table 1. All data points were detected within the standard range of the calibration curves (see Additional files 2, 3, 4, 5, 6, 7, 8, 9, 10, 11, 12).

\section{Discussion}

A 342

This study demonstrates that the consecutive transfer of CSF samples between tubes has significant impact on the measured concentration of $A \beta 42$. Figure $2 \mathrm{~A}$ reveals the potential for concentration levels in neat CSF pools to be artificially reduced from within the 'normal' (that is, CTRL) range to pathological levels in three tube transferals. In a different CSF pool, tested three times (in two different assay kits), this was the case in just one transfer (Figure $2 \mathrm{~B}$ and $\mathrm{C}$ ). This difference between transfer steps 0 to 1 is interesting. It is possible
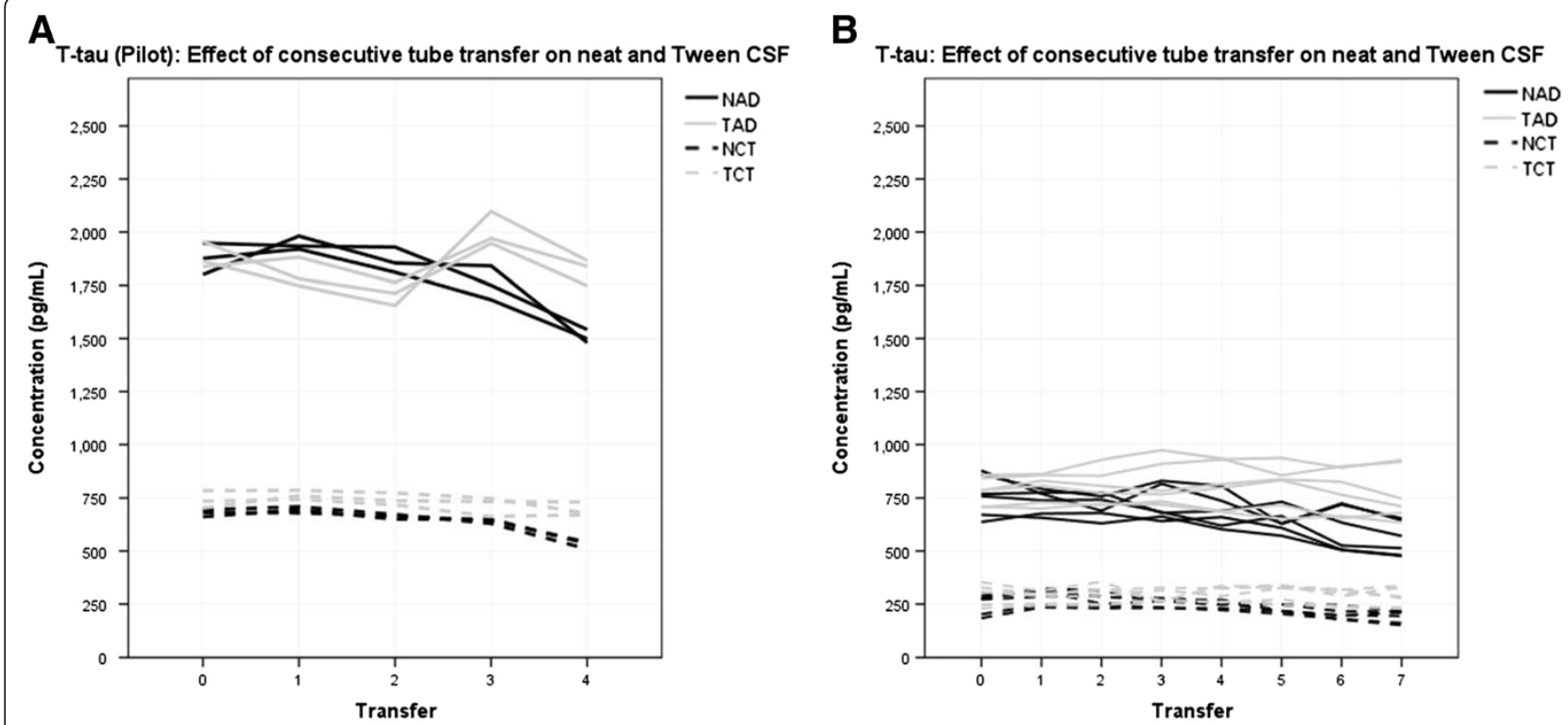

Figure 4 Effect of consecutive tube transfer on total tau. A) Pilot: data represent one assay. Neat and Tween control CSF T-tau concentration did not decrease significantly with consecutive transfer between tubes. Samples were diluted 1:2. Lines of the same type represent within plate replicates. B) Replication: data represent three assays. Neat CSF T-tau concentration decreased significantly with consecutive transfer between tubes. Tween CSF T-tau was not significantly affected by consecutive transfer between tubes. Samples were diluted 1:4. Lines of the same type represent within and between plate replicates, separate days are not distinguished. CSF, cerebrospinal fluid; T-tau, total tau. 
Table 1 Summary of results

\begin{tabular}{|c|c|c|c|c|c|c|c|c|c|}
\hline Analyte & Pool type & $\begin{array}{l}\text { Linear regression } \\
\text { (four transfers) }\end{array}$ & $\begin{array}{c}\text { Confidence } \\
\text { interval }\end{array}$ & $P$ & $\begin{array}{c}\% \\
\text { change } \\
\end{array}$ & $\begin{array}{r}\text { Linear regression } \\
\text { (seven transfers) } \\
\end{array}$ & $\begin{array}{c}\text { Confidence } \\
\text { interval }\end{array}$ & $P$ & $\begin{array}{c}\% \\
\text { change } \\
\end{array}$ \\
\hline \multirow[t]{2}{*}{ (Pilot) } & Neat $A D$ & -36.2 & -47.2 to -25.1 & 0.002 & $27.0 \%$ & & & & \\
\hline & Tween Ad & -9.9 & -16.6 to -3.2 & 0.018 & $5.1 \%$ & & & & \\
\hline \multirow[t]{2}{*}{ Aß42 (Single-plex) } & Neat CTRL & -72.1 & -78.4 to -65.8 & $<0.005$ & $28.6 \%$ & & & & \\
\hline & Tween CTRL & -27.2 & -70.7 to 16.3 & 0.140 & $4.9 \%$ & & & & \\
\hline \multirow[t]{2}{*}{ (Pilot) } & Neat AD & -93.8 & -194.9 to 7.3 & 0.060 & $5.1 \%$ & & & & \\
\hline & Tween Ad & 14.2 & -94.7 to 123.1 & 0.706 & $0.4 \%$ & & & & \\
\hline \multirow[t]{2}{*}{ T-tau } & Neat CTRL & -34.5 & -73.3 to 4.3 & 0.066 & $5.8 \%$ & & & & \\
\hline & Tween CTRL & -14.8 & -38.8 to 10.0 & 0.157 & $1.6 \%$ & & & & \\
\hline \multirow[t]{2}{*}{ (Replication) } & Neat AD & -50.2 & -62.6 to -37.9 & $<0.005$ & $21.8 \%$ & -34.3 & -40.6 to -28.3 & $<0.005$ & $21.1 \%$ \\
\hline & Tween Ad & -22.1 & -31.3 to -12.9 & $<0.005$ & $6.1 \%$ & -25.2 & -29.5 to -20.9 & $<0.005$ & $7.8 \%$ \\
\hline \multirow[t]{2}{*}{ Aß42 (Single-plex) } & Neat CTRL & -83.3 & -110.0 to -56.5 & $<0.005$ & $25.6 \%$ & -52.2 & -64.8 to -39.7 & $<0.005$ & $22.7 \%$ \\
\hline & Tween CTRL & -9.8 & -22.8 to 3.2 & 0.126 & $1.9 \%$ & -34 & -44.9 to -23.1 & $<0.005$ & $8.0 \%$ \\
\hline \multirow[t]{2}{*}{ (Replication) } & Neat AD & -16.9 & -31.7 to -2.2 & 0.028 & $2.6 \%$ & -24.5 & -39.4 to -9.5 & 0.003 & $4.4 \%$ \\
\hline & Tween Ad & 7.1 & -3.4 to 17.6 & 0.164 & $-0.9 \%$ & -106 & -7.4 to 4.1 & 0.558 & $0.2 \%$ \\
\hline \multirow[t]{2}{*}{ T-tau } & Neat CTRL & -3.35 & -11.6 to 4.9 & 0.338 & $-0.1 \%$ & -11.6 & -17.4 to -5.9 & $<0.005$ & $3.5 \%$ \\
\hline & Tween CTRL & 1.1 & -7.5 to 9.6 & 0.789 & $-0.5 \%$ & -0.4 & -4.0 to 3.2 & 0.828 & $0.5 \%$ \\
\hline \multirow[t]{2}{*}{ (Replication) } & Neat AD & -320.1 & -397.0 to -243.1 & $<0.005$ & $11.7 \%$ & -330.2 & -359.3 to -301.0 & $<0.005$ & $16.0 \%$ \\
\hline & Tween Ad & -37.7 & -103.3 to 27.8 & 0.232 & $0.4 \%$ & -53.1 & -78.9 to -27.3 & $<0.005$ & $1.4 \%$ \\
\hline \multirow[t]{2}{*}{ Aß38 (Triplex) } & Neat CTRL & -215.9 & -262.5 to -169.3 & $<0.005$ & $11.7 \%$ & -224.0 & -241.8 to -206.3 & $<0.005$ & $16.1 \%$ \\
\hline & Tween CTRL & 5.1 & -16.2 to 26.4 & 0.608 & $-0.3 \%$ & -38.4 & -53.5 to -23.4 & $<0.005$ & $1.1 \%$ \\
\hline \multirow[t]{2}{*}{ (Replication) } & Neat AD & -669.9 & -786.7 to -552.9 & $<0.005$ & $12.1 \%$ & -676.5 & -724.7 to -628.2 & $<0.005$ & $15.6 \%$ \\
\hline & Tween Ad & 15.3 & -66.7 to 97.4 & 0.689 & $-0.6 \%$ & -121.5 & -174.7 to -68.4 & $<0.005$ & $1.2 \%$ \\
\hline \multirow[t]{2}{*}{ A $\beta 40$ (Triplex) } & Neat CTRL & -55.1 & -652.1 to -449.9 & $<0.005$ & $14.5 \%$ & -513.3 & -554.0 to -472.7 & $<0.005$ & $17.5 \%$ \\
\hline & Tween CTRL & -20.5 & -76 to 35 & 0.434 & $0.1 \%$ & -112.9 & -152.2 to -73.6 & $<0.005$ & $1.6 \%$ \\
\hline \multirow[t]{2}{*}{ (Replication) } & Neat $A D$ & -47.7 & -61.6 to -33.8 & $<0.005$ & $21.0 \%$ & -34.9 & -40.9 to -28.8 & $<0.005$ & $22.2 \%$ \\
\hline & Tween Ad & -10.9 & -18.7 to -3.2 & 0.010 & $1.9 \%$ & -17.3 & -20.7 to -13.9 & $<0.005$ & $4.9 \%$ \\
\hline \multirow[t]{2}{*}{ Aß42 (Triplex) } & Neat CTRL & -74.6 & -99.0 to -50.2 & $<0.005$ & $23.1 \%$ & -41.4 & -62.0 to -40.9 & $<0.005$ & $23.4 \%$ \\
\hline & Tween CTRL & -19.6 & -27.0 to -12.2 & $<0.005$ & $3.1 \%$ & -28.1 & -32.6 to -23.7 & $<0.005$ & $5.5 \%$ \\
\hline
\end{tabular}

The table summarises the results of linear regression and percentage difference calculations for all analytes assayed in this study. Linear regression used the median values of the measurements made at each transfer step. '\% change' represents the average of the percentage difference between each of the relevant number of transfer steps. Bold text is used as a visual aid and has no other meaning. A $\beta$, amyloid beta; AD, Alzheimer's disease; CTRL, control, T-tau, total tau.

that the volume difference between transfer tube 0 and transfer tube 1 in the pilot study could have had an impact on this result. However, this is considered unlikely for reasons discussed below. Alternative suggestions could be that there was a fault with pilot tube 0 (given the close similarity between results in the six independent tubes used in the replication rounds it seems unlikely a fault lay there), an anomaly caused by human or detection error (once again it seems more reasonable to suspect the pilot result), or a difference in the pool matrices which may have altered the behaviour of the analyte in the conditions of the first transfer step. When the $A \beta 42$ results for the neat $A D$ and CTRL pools of the pilot study and the replication study (single-plex and triplex) are compared over the next three transfer steps (Figure 2) a linear trend can be observed between steps 2 to 4 . Furthermore, this trend was demonstrated to continue over steps 5 to 7 in the replication rounds. Table 1 demonstrates very comparable linear regression results, with strongly overlapping confidence intervals, for all $\mathrm{A} \beta 42$ assays conducted.

The addition of the non-ionic surfactant Tween 20 to pooled samples prior to aliquoting had a mitigating effect on the reduction in measured $A \beta 42$ over the transfer series, although reduction was still significant. The storage concentration of Tween 20 used in this study was $0.05 \%$ and after 1:8 sample dilution would have been approximately $0.006 \%$. The generally accepted critical 
micelle concentration (CMC) for Tween 20 is $0.007 \%$, but micelle formation has been shown to initiate at $0.002 \%$ [10]. This suggests that many of the Tween 20 molecules in our samples would still be expected to be in a micelle arrangement during the assay [8] and, as such, be in competition for tube surface and liquid/air interface distribution with other hydrophobic molecules. It has been shown that Tween 20 may also prevent oligomerisation of $A \beta 42$ [9] and this may apply to aggregation more generally. Our study does not elucidate the relative involvement of the two potential mechanisms. Figure 2 and Table 1 show that treating samples with Tween 20 significantly reduced concentration loss per transfer step, relative to their neat counterpart. However, it is worth noting that a dramatic decrease in concentration was observed between transfer steps 5 to 7 in the TCT pool of the replication study. This would be consistent with a decrease in the concentration of Tween 20 molecules (either by complete loss of all Tween 20 molecules or concentration falling far enough below the CMC that micelle numbers no longer formed effective surface competition) sufficient to allow A $\beta 42$ adsorption comparable to that in neat CSF. This effect was not observed in any other pool, but consistent replication (CV\% at Transfer $6=3.1 \%$, at Transfer $7=19.0 \%$ ) suggests it is unlikely to be an error artefact.

\section{A 338}

Data show that the consecutive transfer of CSF samples between tubes has a significant impact on the measured concentration of $A \beta 38$. Figure 3 and Table 1 show a strong linear tendency for concentration reduction in neat CSF. This effect was greatly mitigated in the same samples treated with Tween 20. Over four transfer steps reduction did not reach significance in Tween treated samples, but over all seven steps significant reduction was observed.

\section{A $\beta 40$}

This study demonstrates that the consecutive transfer of CSF samples between tubes has a significant impact on the measured concentration of $A \beta 40$. Figure 3 and Table 1 show a strong linear tendency for concentration reduction in neat CSF. This effect was greatly mitigated in the same samples treated with Tween 20. As with $A \beta 38$, over four transfer steps reduction did not reach significance in Tween treated samples, but over all seven steps significant reduction was observed. It is interesting to note that the starting concentration of $A \beta 40$ was nearly twice that of $A \beta 38$ and, accordingly, linear regression is calculated to follow the same relationship. This demonstrates the apparent concentration dependency of transfer loss rather acutely and is a trend observed in all other analytes.

\section{T-tau}

Data show that consecutive transfer of CSF samples between tubes had a much smaller effect on T-tau concentrations than on the $\mathrm{A} \beta$ peptides. The results of the pilot showed a non-significant trend for a reduction in concentrations of T-tau in neat CSF and no evidence of a reduction following the addition of Tween 20. However, the $P$ values for neat $\mathrm{AD}(P=0.06)$ and control $(P=0.066)$ pools approached significance. Due to the difference in dilution factor between the pilot (1:2) and the replication study (1:4), and given the apparent tendency for protein loss to be concentration dependent, results may not be directly comparable between the two studies. The replication study showed significant reduction in T-tau concentration over seven transfer steps in both neat pools (Figure 4, Table 1). The NAD pool of the replication study reached significant reduction over the initial four transfer steps, thus providing a case that $\mathrm{T}$-tau can be affected within this number of transfers. Tween 20 CSF pools remained unaffected even over the seven transfer steps. Compared with $A \beta$ peptides, neat and Tween 20 T-tau results show a proportionally lower rate of concentration reduction per transfer step (Table 1). Transferring CSF between multiple surfaces could, therefore, create an artificially low $A \beta 42$ to $T$-tau ratio and risk false positive diagnosis of $\mathrm{AD}$ in patients and research participants.

The transfer effects we observed - principally for $A \beta$ peptides, but also, to a lesser extent, for T-tau measurement - may well have significant influences in practice. Not only individual levels of these analytes, but also the ratio of T-tau to $A \beta 42$ are used in clinical and research criteria contributing to diagnosis of $\mathrm{AD}$ [11]. Additionally, it is possible that $A \beta$ peptide ratios could be altered over a number of transfers, given the smaller percentage decrease in peptides 38 and 40 relative to 42 , or by the potential for non-linear reduction, despite a common linear tendency.

\section{Potential confounds Volume}

In a previous study [7], we identified sample volume as a potential confound to the measurement of $A \beta 42$ concentration but not T-tau. There were inter-study volume differences between the pilot and the replication studies and intra-study volume differences in the pilot alone.

In the pilot, although the volume and, therefore, the surface area, of each sample was equivalent in storage $(925 \mu \mathrm{L})$, it was not possible to maintain consistent $200 \mu \mathrm{L}$ volume between all the transferral stage aliquots. Based on the previous data $(0.8 \mathrm{pg} / \mathrm{mL}$ increase per $10 \mu \mathrm{L}$ increase in control CSF $A \beta 42,0.74 \mathrm{pg} / \mathrm{mL}$ increase per $10 \mu \mathrm{L}$ increase in AD CSF $A \beta 42$ ) the following 
discrepancies would be expected relative to an aliquot at $200 \mu \mathrm{L}$ :

$$
\text { Aß42 Tube } 0(215 \mu \mathrm{L}) \text { : }
$$$$
\text { Predicted: Control }=+1.2 \mathrm{pg} / \mathrm{mL} ; \mathrm{AD}=+1.11 \mathrm{pg} / \mathrm{mL}
$$

A 42 Tube $4(110 \mu \mathrm{L})$ :

$$
\text { Predicted: Control }=-7.2 \mathrm{pg} / \mathrm{mL} ; \mathrm{AD}=-6.66 \mathrm{pg} / \mathrm{mL}
$$

Therefore, volume effects are not likely to have been significantly above noise and thus sufficient to bias the results of this study.

In the replication study storage aliquots were $1000 \mu \mathrm{L}$ and transfer aliquots were kept equal at $100 \mu \mathrm{L}$ so as to exclude any effect on volume. It should be noted that the samples used in the pilot and replication studies were of different pools, and the comparisons of this study are based on proportional concentration loss not absolute values. Direct comparisons of A $\beta 42$ between the pilot and replication study are not likely to be valid.

\section{$\mathrm{pH}$}

Murphy et al. [12] have identified that short term storage of CSF samples on dry ice can lower the sample $\mathrm{pH}$ through intrusion of $\mathrm{CO}_{2} . \mathrm{pH}$ change can affect the 'tertiary and quaternary structure, enzymatic rate constants, solubility, tendency to aggregate, susceptibility to chemical degradation and propensity to adsorb to surfaces' of constituent proteins [12]. In our study the original, large volume samples were transported between the Sahlgrenska and London laboratories on dry ice. Once in London they were thawed, divided into aliquots and not subsequently exposed to dry ice. Our results are not, therefore, attributable to this effect.

\section{Further work}

Standard procedure for CSF collection by lumbar puncture [13] (However, it should be noted that touching any part other than the plastic head of the needle may raise sterilisation issues) involves the fluid being passed typically through a 20- to 22-gauge spinal needle (sometimes with a catheter) and dripped into a collection tube. In some cases, and in some centres, CSF is aspirated using a syringe. Baseline and diagnostic tests may then be run on the sample, before it is aliquoted into smaller volume storage tubes. Thus, CSF can encounter two or three different containers before reaching clinical diagnostics, and three or four or more before reaching storage for research or re-testing. Figures 2, 3 and 4 collectively show that this could lead to compromised diagnoses, misleading research data and discrepancy between results. Further attention needs to be directed toward how every step of collection may compromise the accuracy of current assays relative to in vivo reality. A number of these issues have been addressed in other studies $[3,14]$.

\section{Conclusions}

$A \beta 42, A \beta 42$ :T-tau ratio and $A \beta 38: 40: 42$ ratio are now widely used to help diagnose Alzheimer's disease pathology in individuals with cognitive impairment. Between lumbar puncture and laboratory analysis, CSF can be transferred to different containers a number of times, frequently unknown to scientists running the assays, and potentially different between individuals and between sites. We have shown that $A \beta 42$ can be reduced by approximately $25 \%$ simply through tube transfer. Effort should be made to minimise multiple transfers of CSF between surfaces, and record how many such steps a sample has gone through. The addition of $0.05 \%$ Tween 20 to aliquots at initial sample storage may mitigate at least some of these effects and should be the subject of further study.

\section{Additional files}

Additional file 1: Unblind. Original sample ID's matched with their blinded aliases.

Additional file 2: Pilot Ab42. Assay raw data.

Additional file 3: Pilot Ttau. Assay raw data.

Additional file 4: Replication Ab42 \#1. Assay raw data.

Additional file 5: Replication Ab42 \#2. Assay raw data.

Additional file 6: Replication Ab42 \#3. Assay raw data.

Additional file 7: Replication Ttau \#1. Assay raw data.

Additional file 8: Replication Ttau \#2. Assay raw data.

Additional file 9: Replication Ttau \#3. Assay raw data.

Additional file 10: Ab triplex \#1. Assay raw data.

Additional file 11: Ab triplex \#2. Assay raw data.

Additional file 12: Ab triplex \#3. Assay raw data.

\section{Abbreviations}

AD: Alzheimer's disease; Aß42: amyloid beta 1-42 peptide; Cl: confidence interval; CMC: critical micelle concentration; CSF: cerebrospinal fluid;

CTRL: control sample; NAD: neat Alzheimer's disease; NCT: neat control; PP: polypropylene; TAD: Tween Alzheimer's disease; TCT: Tween control; T-tau: Total tau.

\section{Competing interests}

The authors declare that they have no competing interests.

\section{Authors' contributions}

JT conceived of the study, participated in its design, conducted the immunoassays and drafted the manuscript. RWP performed the statistical analysis and helped to draft the manuscript. JMS participated in coordination and helped to draft the manuscript. $\mathrm{HZ}$ participated in study design and coordination, and helped to draft the manuscript. All authors read and approved the final manuscript.

\section{Acknowledgements}

We gratefully acknowledge the support of the Leonard Wolfson Experimental Neurology Centre, the NIHR Queen Square Dementia BRU. The Dementia Research Centre is an Alzheimer's Research UK Coordinating Centre. 


\section{Author details}

'Department of Molecular Neuroscience, Institute of Neurology, University College London, Queen Square, London, UK. '² Dementia Research Centre, Department of Neurodegeneration, Institute of Neurology, University College London, Queen Square, London, UK. ${ }^{3}$ Institute of Neuroscience and Physiology, Department of Psychiatry and Neurochemistry, The Sahlgrenska Academy at the University of Gothenburg, Gothenburg, Sweden.

Received: 30 July 2013 Accepted: 8 January 2014

Published: 28 Jan 2014

\section{References}

1. Schoonenboom NS, Mulder C, Vanderstichele H, Van Elk EJ, Kok A, Van Kamp GJ, Blankenstein MA: Effects of processing and storage conditions on amyloid beta (1-42) and tau concentrations in cerebrospinal fluid: implications for use in clinical practice. Clin Chem 2005, 51:189-195.

2. Bateman RJ, Wen G, Morris JC, Holtzman DM: Fluctuations of CSF amyloid-beta levels: implications for a diagnostic and therapeutic biomarker. Neurology 2007, 68:666-669.

3. Bjerke M, Portelius E, Minthon L, Wallin A, Anckarsater $H$, Anckarsater R, Andreasen N, Zetterberg $H$, Andreasson U, Blennow K: Confounding factors influencing amyloid Beta concentration in cerebrospinal fluid. Int J Alzheimers Dis 2010, 15:1-11.

4. Hansson O, Zetterberg H, Buchhave P, Londos E, Blennow K, Minthon L: Association between CSF biomarkers and incipient Alzheimer's disease in patients with mild cognitive impairment: a follow-up study. Lancet Neurol 2006, 5:228-234.

5. Perret-Liaudet A, Pelpel M, Tholance Y, Dumont B, Vanderstichele H, Zorzi EIMoualij B, Schraen S, Moreaud O, Gabelle A, Thouvenot E, Thomas-Anterion C, Touchon J, Krolak-Salmon P, Kovacs GG, Coudreuse A, Quadrio I, Lehmann S: Cerebrospinal fluid collection tubes: a critical issue for Alzheimer disease diagnosis. Clin Chem 2012, 58:787-789.

6. Andreasen N, Hesse C, Davidsson P, Minthon L, Wallin A, Winblad B, Vanderstichele $H$, Vanmechelen $E$, Blennow $K$ : Cerebrospinal fluid beta-amyloid(1-42) in Alzheimer disease: differences between early- and late-onset Alzheimer disease and stability during the course of disease. Arch Neurol 1999, 56:673-80.

7. Toombs J, Paterson RW, Lunn MP, Nicholas JM, Fox NC, Chapman MD, Schott $J M$, Zetterberg $\mathrm{H}$ : Identification of an important potential confound in CSF AD studies: aliquot volume. Clin Chem Lab Med 2013, 51:2311-2317.

8. Pica-Mendez AM, Tanen M, Dallob A, Tanaka W, Laterza OF: Nonspecific binding of $A \beta 42$ to polypropylene tubes and the effect of Tween-20. Clin Chim Acta 2010, 411:1833.

9. LeVine $\mathrm{H}$ 3rd: Alzheimer's beta-peptide oligomer formation at physiologic concentrations. Anal Biochem 2004, 335:81-90.

10. Deechongkit S, Wen J, Narhi LO, Jiang Y, Park SS, Kim J, Kerwin BA: Physical and biophysical effects of polysorbate 20 and 80 on darbepoetin alfa. J Pharm Sci 2009, 98:3200-3217.

11. Dubois B, Feldman HH, Jacova C, Dekosky ST, Barberger-Gateau P, Cummings J, Delacourte A, Galasko D, Gauthier S, Jicha G, Meguro K, O'brien J, Pasquier F, Robert P, Rossor M, Salloway S, Stern Y, Visser PJ, Scheltens P: Research criteria for the diagnosis of Alzheimer's disease: revising the NINCDS-ADRDA criteria. Lancet Neurol 2007, 8:734-46.

12. Murphy BM, Swarts S, Mueller BM, van der Geer P, Manning MC, Fitchmun MI: Protein instability following transport or storage on dry ice. Nat Methods 2013, 10:278-279.

13. Shlamovitz GZ, Shah NR: Lumbar Puncture Technique. 2012. http://emedicine. medscape.com/article/80773-technique. Accessed 28 March 2013.

14. del Campo M, Mollenhauer B, Bertolotto A, Engelborghs S, Hampel H, Simonsen AH, Kapaki E, Kruse N, Le Bastard N, Lehmann S, Molinuevo JL, Parnetti L, Perret-Liaudet A, Sáez-Valero J, Saka E, Urbani A, Vanmechelen E, Verbeek M, Visser PJ, Teunissen C: Recommendations to standardize preanalytical confounding factors in Alzheimer's and Parkinson's disease cerebrospinal fluid biomarkers: an update. Biomark Med 2012, 6:419-430.

\subsection{6/alzrt236}

Cite this article as: Toombs et al: Amyloid-beta 42 adsorption following serial tube transfer. Alzheimer's Research \& Therapy 2014, 6:5

\section{Submit your next manuscript to BioMed Central and take full advantage of:}

- Convenient online submission

- Thorough peer review

- No space constraints or color figure charges

- Immediate publication on acceptance

- Inclusion in PubMed, CAS, Scopus and Google Scholar

- Research which is freely available for redistribution 